\title{
Firearms and Suicides in US States
}

\author{
Justin Thomas Briggs* \\ Alexander Tabarrok* \\ jbriggs3@gmu . edu \\ atabarro@gmu . edu
}

June 2013

\begin{abstract}
This study investigates the relationship between firearm prevalence and suicide in a sample of all U.S. states over the years 2000-2009. We find strong, positive effects of gun prevalence on suicide using OLS estimation, across a variety of measures for gun possession, and with several sets of controls. When using instrumental variable estimation, the effect remains significant, despite also finding significant evidence that gun ownership causes substitution towards gun-suicide rather than other methods of suicide. There is also evidence for nonlinearities in the effects of guns on suicide.
\end{abstract}

JEL Classifications: I12, I19, K10

*Department of Economics, George Mason University, Fairfax, Virginia. 


\section{INTRODUCTION}

Firearms play a unique role in public discourse. The U.S. Constitution protects the right to bear arms. For some, this right represents an important safeguard against tyranny. For hunters and sportsmen, firearms enable a vibrant recreation. Firearms also play an important but largely unknown role in selfdefense. Yet in 2010, the latest year for which there are complete figures, there were 19,392 suicides, 11,078 homicides, and 606 accidental deaths by firearm, in addition to 73,505 non-fatal injuries by firearms (Centers for Disease Control and Prevention, 2012). Unfortunately, even basic information such as how many households own firearms is irregular and partly as a result there is little scientific consensus on how firearms influence violent injuries.

Although the effect of firearms on homicides has been a topic of recurring debate, less attention is often given to suicide, despite there being more deaths attributable to suicide than to homicide. This may be in part because people view suicide as a private decision only affecting friends and family of the deceased, although this impact should not be minimized. But many psychological studies find that suicides are frequently impulsive decisions (e.g. Simon et al., 2002), and that less than $10 \%$ of suicide survivors go on to successfully re-attempt suicide over the long term (Owens et al., 2002). Few suicides appear to be considered choices.

In this study we specifically explore the relationship between firearm ownership rates and rates of suicide, using a newly constructed dataset covering US states from 2000-2009. We utilize all data from the first state-level representative survey of gun ownership, as well as four other proxies thereof, including one new to the literature. In addition, we will develop instruments for firearm ownership rates.

\section{BACKGROUND}

The United States stands out among developed countries for having the most firearms (Geneva Graduate Institute of International Studies, 2007). The U.S. also has the highest rate of suicide by firearm of any developed country. Indeed, the rate of suicide is on par with the rate of traffic deaths in 2009 , there were 11.0 traffic deaths per 100,000 , and 12.0 suicides - and the majority of suicides 
are by firearm. However, the total suicide rate is also lower than in many countries with fewer firearms. More generally, cross-country studies tend to show no relationship between firearms and suicide (Killias et al., 2001; Krug et al., 1998).

Within the U.S, ecological and case-study approaches both appear to show a strong positive association between firearms and suicides by firearm (e.g. Azrael et al., 2004; Brent et al., 1994; Kleck and Patterson, 1993). What is less clear is whether there is an association between firearm ownership and overall suicide. After all, in the absence of a firearm, there are several other methods of suicide, most predominately suffocation and poisoning, and a determined individual could simply substitute the means to achieve the same end. For example, Sloan et al. (1990) compare Vancouver and Seattle and find that Seattle has more firearms and suicides by firearm than Vancouver but it has more overall suicides in only the 15-24 age group which suggests a significant degree of method substitution. On the other hand, policy change studies have shown that decreased access to firearms can decrease suicide overall. In one careful study, Leigh and Neill (2010) find that the mandatory buyback of $20 \%$ of the stock of firearms in Australia in 1997 (which halved the number of households holding firearms) led to nearly an $80 \%$ reduction in suicides. Similarly, Lubin et al. (2010) show that when drafted soldiers in the Israeli military were prohibited from bringing their guns home with them for the weekend, suicide fell by $40 \%$, owing to a fall in suicides over weekends that was not accompanied by an increase in weekday suicides.

Is there a causal relationship between firearm ownership and suicides? In this paper we will focus on how the total numbers of guns in the hands of citizens affects suicide rates on the margin. There are three potential causal pathways by which increased firearm ownership may increase successful suicide. First is the weapon instrumentality effect, which posits that if guns are inherently more lethal than other methods then they would make attempts more likely to be successful. In 2001, $85 \%$ of suicide attempts by gun were lethal, compared with 69\% for the next most lethal method (suffocation/inhalation) (Vyrostek et al., 2004). Intent, however, is a confounding variable. One would suspect that those more intent on suicide would choose more lethal methods, although the evidence for this proposition is weak (compare Peterson et al. (1985) with Hamdi et al. (1991)). Second is the method selection (or induction) hypothesis, positing that the actual or perceived "ease" of committing suicide by gun may make it 
more likely to happen (because it is thought to be either quicker, simpler, or more likely to be successful). Psychologists have shown that suicidal thoughts are often only brief, and many suicide attempts are impulsive (Hawton, 2007; Simon et al., 2002), so the absence of an effective immediate means may prove a deterrent. Interviews with people who failed at suicide often indicate that methods were chosen according to ease of availability (Peterson et al., 1985; Skopek and Perkins, 1998). Third, if it is an easier, quicker, and more certain means of self-destruction than others, it may reduce the chances of successful outside intervention.

The only plausible source of reverse causality (as opposed to correlation) is that an individual may purchase a firearm for the purpose of committing suicide ${ }^{1}$. But even if all firearm suicides represented a new gun purchase, this would account for only $0.2 \%$ of firearm purchases ${ }^{2}$ so this does not appear to be a potent form of reverse causality.

Firearms may also be related to suicide via other unobserved avenues that lead to correlation without causation, such as prevalence of generalized mistrust, mental health issues, or morbid thoughts. Or there may be no causal relationship at all.

\section{DATA}

We will analyze state-level rates of suicide, considering both firearm- and non-firearm- varieties as well as overall rates, in several samples covering the decade 2000-2009. The mortality data cover substantially all such deaths in the US, and are from Centers for Disease Control and Prevention's (2012) WISQARS compressed mortality file. For context, we provide national trends in suicides in Figure 1. Suicides rose slightly over the study period, particularly in the category of non-firearm suicides. Summary statistics for all data are in Table A.1.

\subsection{FIREARM MEASURES}

The variable of interest is the percentage of individuals living in households with at least one firearm ${ }^{3}$. A major shortcoming of much earlier work is that no data was available that directly measured

\footnotetext{
${ }^{1}$ Wintemute et al. (1999) present evidence that at least some people do purchase firearms for the purpose of committing suicide.

${ }^{2}$ In 2009 e.g., there were 18,735 firearm suicides and 8,968,180 net new firearms.

${ }^{3}$ The literature implicitly assumes that household ownership means enhanced access to a firearm although this assumption requires that there is some barrier to buying or obtaining a firearm in order to commit suicide. There are several reasons to think
} 
Figure 1: Trends in suicide rates 1985-2010 (per 100,000)

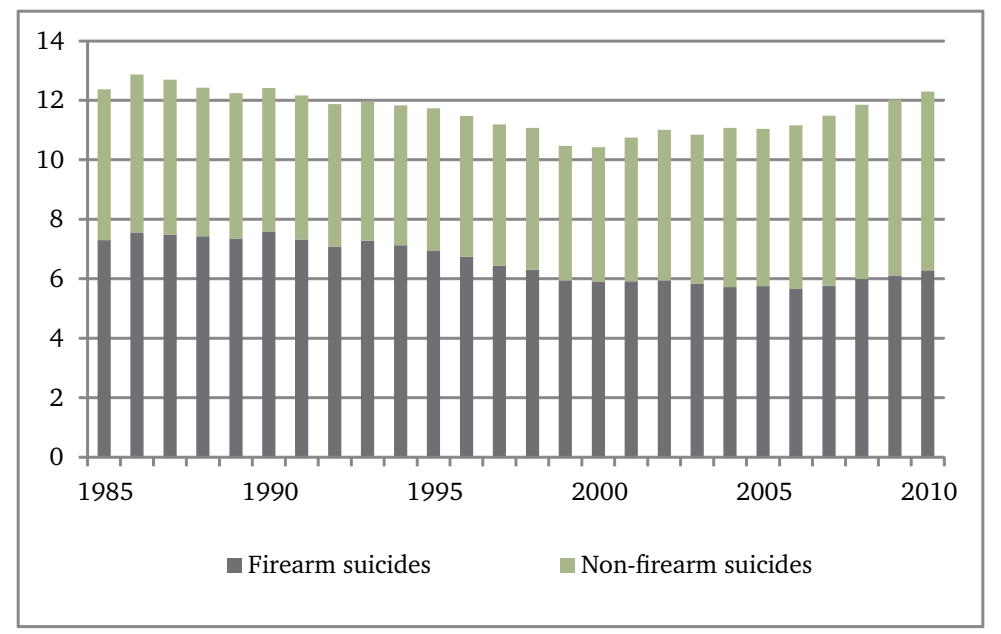

gun ownership in a representative way in all states. Most states do not require registration or licensing, so consulting administrative records is not an option (Vernick and Hepburn, 2003). In this paper we use data from the first and only national survey that is representative at the state level. The survey data was collected in the large Behavioral Risk Factor Surveillance System (Centers for Disease Control and Prevention, 2010) telephone survey conducted by the states under the guidance of the CDC. The question "Are any firearms kept in or around your home?" (or a slight variation thereof) was asked in 2001, 2002, and 2004. After 2004, the question was discontinued. Respondents who refuse to answer, or do not know, together accounting for 4 percent of the total or less, are excluded. ${ }^{4}$

Although we believe the BRFSS measure is the best survey measure yet to be used, it still remains flawed. We therefore test for robustness using a variety of other proxies. Namely, rates of Google searches for gun-related terms, the proportion of suicides that are committed with a gun, the rate of background checks for gun purchases and the rate of accidental death by firearm. The latter three proxies we combine into a gun composite index using their first principal component.

that although by no means insurmountable, the need to find and purchase a gun may be enough to deter in many cases. First, it takes time and effort to find and go to a firearm dealer, choose a weapon, get a background check, and obtain it (possibly after a mandatory waiting period), and this may give time for reflection and re-evaluation. Second, for many the price of a firearm and ammunition is not trivial, starting at several hundred dollars. Third, a potentially suicidal individual may be paralyzed by oppressive thoughts that preclude seeking to purchase a firearm. Finally, there may be cognitive barriers that cause an individual to think obtaining and properly using one would be harder than it is. For there to be some effect of current possession rates, any marginal barrier will suffice. Ownership is likely also correlated with other measures of ease of access.

${ }^{4}$ California and Hawaii each had a missing observation that was estimated using the other observations and national trends. 
We use rates of Google searches containing any of the following keywords: gun, rifle, pistol, handgun. (Google, 2012) Available beginning in 2004, these rates represent the relative frequencies of these search terms within the state, compared with other searches that year. Used for the first time here, this "Google Composite Gun Searches" measure proxies for gun possession under the assumption that interest in guns is proportional to household ownership rates, and rates of Google searches for these terms accurately measure interest. ${ }^{5}$ This is not implausible, as several studies do find Google Searches to be useful indicators of consumer sentiment (Choi and Varian, 2012; Della Penna and Huang, 2010), and as we show below, this index correlates well with the BRFSS measure.

Next, we use a commonly cited proxy for gun ownership - the proportion of suicides that are committed with a gun. This is constructed from CDC data, has been shown to have high cross-sectional correlation with survey measures of ownership (Azrael et al., 2004), and is available for all years 20002009. Although this is commonly used, there has been some question about how accurate it is (Duggan, 2001; National Academy of Sciences, National Research Council, 2004; Shenassa et al., 2006), with e.g, the latter finding it not strongly related to self-reported neighborhood level of firearm carrying and availability among juveniles.

The rate of background checks for gun purchases for a given state is available for the full sample, 2000-2009, from the Federal Bureau of Investigation's (2012) National Instant Criminal Background Check System (NICS). If background checks measure gun purchases and purchases are proportional to existing ownership rates (such as if firearms depreciate, become obsolete, and are replaced at a certain rate), then they would be a good proxy for firearm ownership rates. Unfortunately the concerns about background checks are well known: they are only conducted by federally-licensed firearm dealers, and many purchases are conducted outside these dealers; a background check may represent zero, one, or many gun purchases ${ }^{6}$; and due to varying state regulations, raw background checks may not be comparable over time or between states. For example, Kentucky began requiring background checks for concealed carry permits in 2006 , greatly inflating numbers. To the extent possible, these internal

\footnotetext{
${ }^{5}$ This measures the state-specific variation in gun searches, averaged over a year. As such many outside drivers of interest in guns, such as national gun-control debates or incidences of widely-covered shootings, would not be included.

${ }^{6}$ In practice, one is almost certainly the modal number of guns purchased per adjusted background check. In addition we have been able to confirm that at a national level over the 10 year study period, the Pearson correlation coefficient between NICS checks and net new firearms in the US (domestic firearm production plus net firearm imports) (Bureau of Alcohol, Tobacco, Firearms and Explosives, 2011) is 0.78, significant at the 1\% level.
} 
comparability issues have been corrected in our data. Nonetheless, the data remain imperfect.

The rate of accidental death by firearm would perhaps be one of the most defensible proxies, except for the fact that it is fairly rare and as a Poisson random variable with low expected value, it likely suffers truncation error.

In an attempt to overcome weaknesses and combine the strengths of some proxies we have constructed a composite measure of firearm ownership ("Gun Possession Composite") from the first principal component of these three proxies: percent suicides by gun, background check rates, and rates of accidental death by gun. This captures over $74 \%$ of the total variation of the component variables, all of which contribute positively, and it correlates strongly $(\rho=0.84)$ with the BRFSS ownership measure.

Table 1: Characteristics of gun measures

\begin{tabular}{|c|c|c|c|c|c|c|c|}
\hline Measure & $\begin{array}{l}\text { Gov't health } \\
\text { survey }\end{array}$ & $\begin{array}{l}\text { Samples } \\
\text { non-inst'l } \\
\text { phone users }\end{array}$ & $\begin{array}{l}\text { Internet users } \\
\text { of Google } \\
\text { search only }\end{array}$ & $\begin{array}{l}\text { Sometimes } \\
\text { sparse }\end{array}$ & $\begin{array}{l}\text { Behavioral } \\
\text { proxy }\end{array}$ & $\begin{array}{l}\text { Requires pro- } \\
\text { portionality } \\
\text { assumption }\end{array}$ & $\begin{array}{l}\text { May capture } \\
\text { purpose- } \\
\text { bought guns }\end{array}$ \\
\hline BRFSS & $\mathrm{X}$ & $\mathrm{x}$ & & & & & \\
\hline Google gun searches & & & $\mathrm{X}$ & $\mathrm{X}$ & $\mathrm{X}$ & & $\mathrm{X}$ \\
\hline$\%$ of suicides by gun & & & & & $\mathrm{x}$ & & $\mathrm{X}$ \\
\hline Acc. deaths by gun & & & & $\mathrm{x}$ & $\mathrm{x}$ & & \\
\hline Background searches & & & & & & $\mathrm{x}$ & $\mathrm{X}$ \\
\hline
\end{tabular}

In Table 1, we provide a comparison of some salient features of the gun measures used in this paper. As the chart makes clear, no one measure is ideal. By using a wide variety, we can have enhanced confidence if and when they yield similar results. Over the study period, at a national level, all firearm measures except that of background checks show a slight downward decline ${ }^{7}$. Background checks (consistent with net new firearms) increased over the period, even after accounting for the increase in the number of households, suggesting that proportionally fewer households are holding more firearms each.

All measures show substantial variation across states. Cross-sectionally, the four measures of gun possession we consider are highly correlated, and BRFSS is correlated with all other proxies at $\rho>0.8$.

\footnotetext{
${ }^{7}$ National polls such as the general social survey (GSS) (Smith et al., 2011) and Gallup polls (Gallup, 2011) also show declines over the period.
} 
Figure 2: Scatter plots of gun possession measures

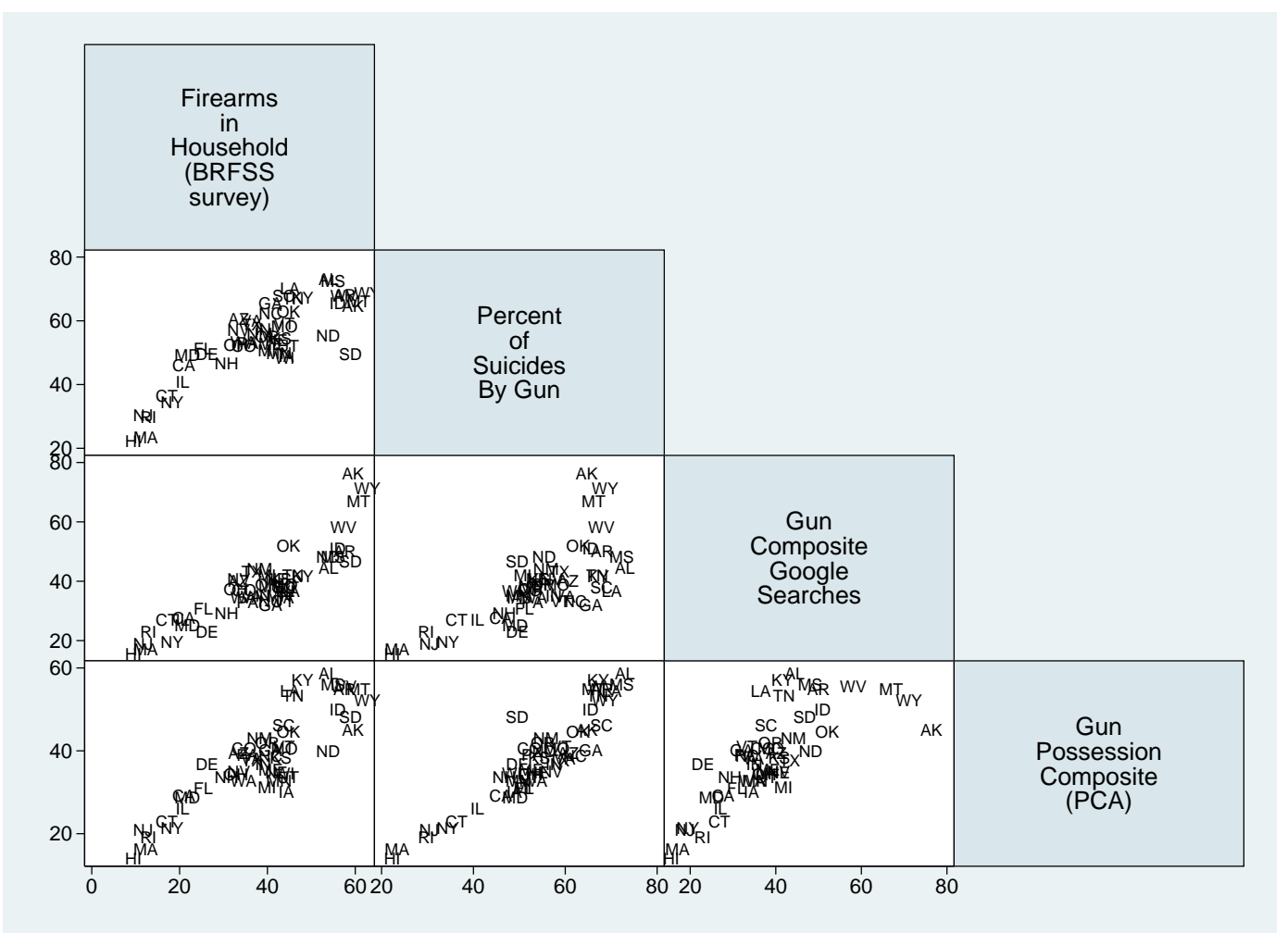

NotE: All scatter plots are of a three year average $(2001,2002,2004)$ to coincide with the BRFSS sample years, except the GunCompSearches vs BRFSS scatter plot, where only 2004 overlaps.

Scatter plots are shown in Figure 2 for years in which there is an overlap. Finally, we use Cronbach's alpha to evaluate whether these appear to measure the same construct, finding $\alpha=.84$, which denotes good internal consistency, giving increased confidence that these measures do in fact represent the latent gun possession variable.

\subsection{OTHER CONTROLS}

We use a number of controls common in the literature. Our baseline controls include the population (US Census Bureau, 2012a), poverty rate (\% under the poverty line, all ages) (US Census Bureau, 2012d), annual average unemployment rate (Bureau of Labor Statistics, 2012), percent urban land area (Demographia, 2012), percent urban population (US Census Bureau, 2012b), Gini coefficient of house- 
hold income inequality, calculated from US Census Bureau (2012a) data, prevalence of drug and/or alcohol abuse or dependence in the population aged $\geq 12$ (Substance Abuse and Mental Health Services Administration, 2012), and prevalence of frequent mental distress (FMD) ${ }^{8}$ among non-institutionalized adults (Centers for Disease Control and Prevention, 2010).

Additionally, we use demographic controls for groups at high risk for suicide, including the percent of males age 65 and higher, and the percent white. We use time-specific fixed effects to control for any time-varying factors that affect all states. Finally, we control for regional variation using census region fixed effects. If for example the southeast region were culturally more predisposed to gun violence (Nisbett and Cohen, 1996; Rosenfeld et al., 2001), this should capture that effect.

As a baseline, we believe these controls represent a good set of outside factors affecting suicide, are likely exogenous, and should not omit too much. Further controls are explored later in the paper.

\section{Approach and Results}

We attempt to ascertain the association between firearm possession rates and intentionally selfinflicted fatal injuries. As discussed above, this is fraught with difficulty because of the variety of confounding influences and because of difficulties in measuring possession rates. We attempt to improve our knowledge about this association by using a multifaceted approach. First, to evaluate sensitivity of these results to omitted variables and endogeneity biases, we use a variety of controls for potential drivers of suicides, ranging from a very minimal specification to a very complete set of controls. Second, we use a pair of instruments for gun possession, in an attempt to tease out causality. Finally, as mentioned, we explore four measures of gun possession.

The basic model is of the following form:

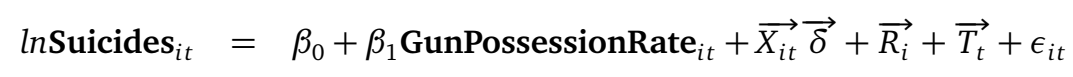

We wish to evaluate $\beta_{1}$, the effect of gun possession rates on Suicides (the number of suicides, or some

\footnotetext{
${ }^{8} \mathrm{FMD}$ is measured by counting those answering 14 or more days to the question: "Thinking about your mental health, which includes stress, depression, and problems with emotions, for how many days during the past 30 days was your mental health not good?". One state-year observation was missing and was estimated.
} 
subset thereof $)^{9}$, across U.S. states $i$ and years $t$, after controlling for a set of time and state-varying controls $\overrightarrow{X_{i t}}$ as discussed elsewhere, always including fixed effects for year $\left(T_{t}\right)$ and region $\left(R_{i}\right)$, as well as $\log$ population. Standard errors are clustered by state in all regressions. We do not use state fixed effects because of the durability of firearms, and because the rates of firearm possession have little actual year to year variance over the study period.

The section proceeds by reviewing OLS regression results using the BRFSS survey measure of gun possession. Then we review the use of varying sets of controls in this regression, before moving on to consider other measures of gun possession in a similar fashion. Next, we consider the possibility nonlinear effects of gun possession. Finally, we use an instrumental variable approach on the same specifications.

In all cases, we run three sets of regressions: First on the gun suicide rate, then the non-gun suicide rate and finally the overall level of suicides. The overall rate is perhaps the most important rate but this is also the most complicated to interpret and the two earlier regressions will aid in interpretation. If guns are to have an effect at all, we expect this to appear at a minimum in the gun-suicide regressions. Guns should affect gun suicides most of all, for example, and if guns affect suicides overall, it should be through this rate. We investigate the non-gun suicide rate primarily to assess whether there is substitution. For example, if people choose to use a gun simply because it's convenient, but would have performed the same act even without a gun, we should see a negative coefficient on non-gun suicide rates. We may also see evidence of a third causal variable across the regressions. If, for example, increased social anomie increases gun purchases and all types of suicides we should see a positive correlation between gun possession and non-gun suicide. Careful examination of all three regressions will help in interpretation.

\subsection{BRFSS}

The most direct and possibly the most representative measure of gun possession rates in U.S. states comes from the BRFSS survey conducted in 2001, 2002, and 2004. We begin by analyzing suicide with this data. To get a quick sense, first see Figure 3. The left-hand plot shows the simple relationship

\footnotetext{
${ }^{9}$ We refer to regressions on the suicide rate later because of the interpretation of the regression coefficients as a semi-elasticity.
} 
between gun possession and suicide. The right hand side shows the same relationship, after controlling for other differences between states using our baseline controls (discussed above). There is a clear positive association between gun possession and suicide in both versions.

Figure 3: Scatter plots of BRFSS gun possession versus suicide

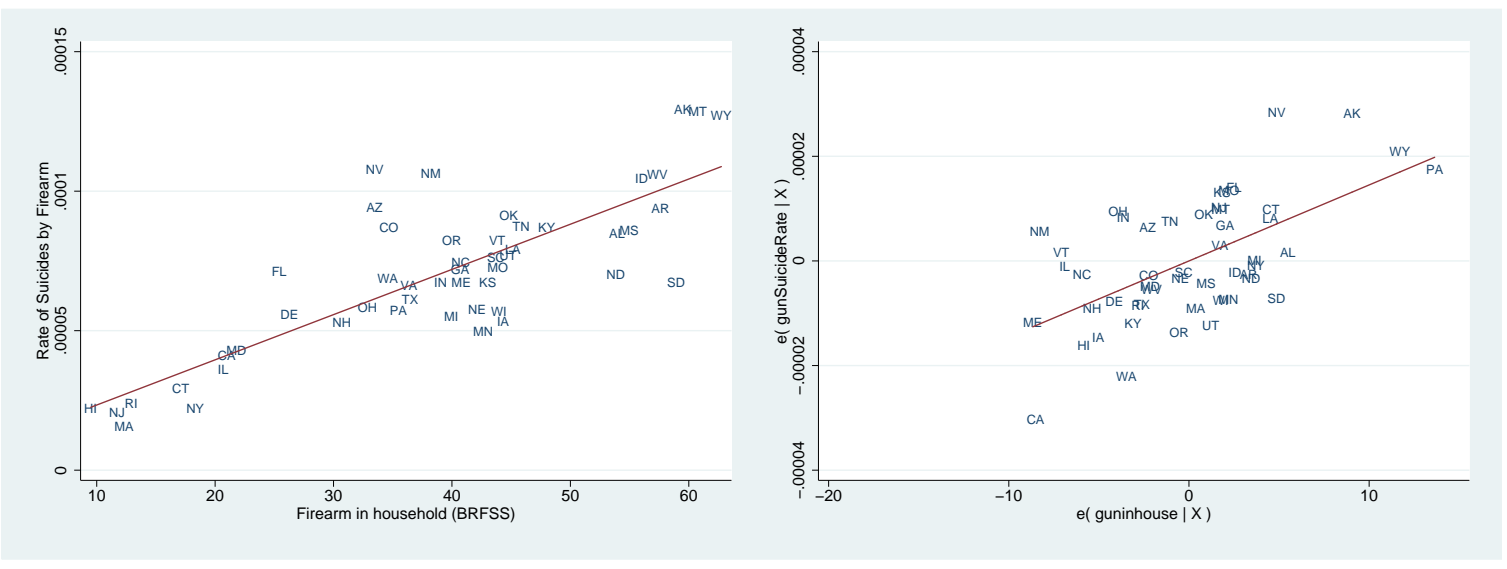

NotE: All scatter plots use a three year average $(2001,2002,2004)$ to coincide with the BRFSS sample years. The plots show gun possession rates on the vertical axis and firearm suicide rates on the horizontal. The left-hand plot is a simple relationship. The right-hand plot is conditional upon the baseline controls. (In these charts we are viewing rates for visual clarity; following regression analyses consider log counts while also controlling for log population.)

\subsubsection{BASIC OLS APPROACH}

More formal results are shown in Table 2. Following the model above, we use the baseline set of controls for three sets of regressions on suicide. In column (1), the dependent variable is gun suicide, in column (2) it is non-gun suicide and in column (3) all suicides. The BRFSS gun possession variable ('guninhouse') is the independent variable of interest. The OLS estimate $\left(\hat{\beta}_{1}\right)$ shows that a one percentage point rise in the prevalence of individuals having firearms in their household is associated with an expected mean increase of $1.7 \%$ in the number of gun suicides (significant at the $1 \%$ level) ${ }^{10}$. In the results for non-firearm suicides in column (2), we do see some sign of method substitution for suicide - a $1 \%$ rise in gun prevalence is associated with a $0.8 \%$ decline in non-gun suicides — but the amount of substitution is not enough to mitigate an overall rise. As shown in column (3) a $1 \%$ increase

\footnotetext{
${ }^{10}$ It is worth noting that any association represents a lower bound on what the association would be if there were more constraints on acquiring new guns, such as a ban on acquisition, because then the prevailing rates would be more 'binding.'
} 
in gun prevalence is associated with an overall $0.5 \%$ rise in the number of suicides (significant at the $10 \%$ level)..$^{11}$

\subsubsection{Varying Specifications}

Next we investigate the robustness of these results to varying the set of controls used. In addition to the 'baseline' specification used above, we will utilize a 'minimal' and 'full' specification. The minimal specification is a subset of baseline, including only demographic controls, percent urban land \& population, and unemployment \& poverty rates in addition to population and year \& regional fixed effects. These controls were selected for being as independent as possible from proposed causal mechanisms for suicide, while still capturing much of the diversity between states. It may suffer from omitted variables bias but is unlikely to have serious endogeneity issues.

The full specification is a superset of the baseline. In addition to the baseline controls, it includes median household income (US Census Bureau, 2012d), percent of children living in a single mother family, percent of divorced adults (US Census Bureau, 2012a), and distance in miles to the nearest hospital emergency room ${ }^{12}$, which is meant to proxy for access to mortality-reducing health care (Health Forum and ESRI, 2008; US Census Bureau, 2012c), and a measure of social connectedness ${ }^{13}$, which is often thought of as a factor in preventing suicide (Corporation for National \& Community Service, 2012). The full specification has the reverse strengths and weaknesses of the minimal: while it is fairly unlikely to suffer from omitted variables bias, it is more likely to suffer from endogeneity issues.

Results are presented in columns (4) - (9) of Table 2. Broadly, they are similar to the baseline specification for both the minimal and full specifications. The minimal specification gives effectively the same results as the baseline across gun, non-gun, and overall suicide. The full specification shows a slightly weaker association with gun suicide, with one percentage point increase in gun prevalence

\footnotetext{
${ }^{11}$ To confirm that our results are not being driven by the use of the pooled multi-year sample, Table A.2 shows results from the same models operating instead on 50-state sample which uses mean values over the three year period. Results are substantially the same, with effects of possession on suicide being slightly stronger.

${ }^{12}$ This was calculated as the population-weighted state-average distance from each census tract (avg. population 4,322) population centroid to the nearest hospital with emergency room and surgery.

${ }^{13}$ Social connectedness is based upon answers to questions in the Civil Life in America Survey. Specifically, we calculate the first principal component of how often people answer "frequently" to the questions of whether they 'talk to' or 'do favors for' neighbors, and percentages answering "yes" to whether they participate in any of the following groups: School group, neighborhood or community association; service or civic association; sports or recreation association; church, synagogue, mosque or religious institution; or, any other type of organization.
} 
Table 2: BRFSS (2001/2/4) firearm ownership and suicide (baseline, minimal, and full controls)

\begin{tabular}{|c|c|c|c|c|c|c|c|c|c|}
\hline & \multicolumn{3}{|c|}{ Baseline } & \multicolumn{3}{|c|}{ Minimal } & \multicolumn{3}{|c|}{ Full } \\
\hline & GunSui & NongunSui & Suicide & GunSui & NongunSui & Suicide & GunSui & NongunSui & Suicide \\
\hline & (1) & (2) & (3) & (4) & (5) & (6) & (7) & (8) & (9) \\
\hline guninhouse & $\begin{array}{c}0.017^{\text {**** }} \\
(0.005)\end{array}$ & $\begin{array}{c}-.008^{* *} \\
(0.004)\end{array}$ & $\begin{array}{c}0.005^{*} \\
(0.003)\end{array}$ & $\begin{array}{c}0.016^{* * *} \\
(0.005)\end{array}$ & $\begin{array}{c}.007^{*} \\
(0.004)\end{array}$ & $\begin{array}{c}0.005^{*} \\
(0.003)\end{array}$ & $\begin{array}{c}0.014^{* * *} \\
(0.005)\end{array}$ & $\begin{array}{c}-.011^{* * *} \\
(0.003)\end{array}$ & $\begin{array}{l}0.003 \\
(0.003)\end{array}$ \\
\hline povertyRate & $\begin{array}{l}-.014 \\
(0.018)\end{array}$ & $\begin{array}{l}-.006 \\
(0.015)\end{array}$ & $\begin{array}{l}-.005 \\
(0.012)\end{array}$ & $\begin{array}{l}-.012 \\
(0.015)\end{array}$ & $\begin{array}{l}-.018 \\
(0.013)\end{array}$ & $\begin{array}{l}-.009 \\
(0.011)\end{array}$ & $\begin{array}{l}-.034 \\
(0.022)\end{array}$ & $\begin{array}{l}0.006 \\
(0.021)\end{array}$ & $\begin{array}{l}-.012 \\
(0.014)\end{array}$ \\
\hline unemployment & $\begin{array}{l}0.05^{*} \\
(0.03)\end{array}$ & $\begin{array}{l}0.026 \\
(0.025)\end{array}$ & $\begin{array}{l}0.034 \\
(0.024)\end{array}$ & $\begin{array}{c}0.054^{*} \\
(0.03)\end{array}$ & $\begin{array}{l}0.033 \\
(0.028)\end{array}$ & $\begin{array}{c}0.04 \\
(0.024)\end{array}$ & $\begin{array}{l}-.018 \\
(0.027)\end{array}$ & $\begin{array}{l}-.003 \\
(0.02)\end{array}$ & $\begin{array}{l}-.010 \\
(0.017)\end{array}$ \\
\hline pctUrbanLand & $\begin{array}{c}-.015^{* *} \\
(0.007)\end{array}$ & $\begin{array}{c}-.007^{* * *} \\
(0.002)\end{array}$ & $\begin{array}{c}-.008^{* *} \\
(0.003)\end{array}$ & $\begin{array}{c}-.015^{* *} \\
(0.006)\end{array}$ & $\begin{array}{c}-.008^{* * *} \\
(0.002)\end{array}$ & $\begin{array}{c}-.008^{* *} \\
(0.003)\end{array}$ & $\begin{array}{c}-.011^{*} \\
(0.006)\end{array}$ & $\begin{array}{c}-.005^{* * *} \\
(0.002)\end{array}$ & $\begin{array}{c}-.005^{*} \\
(0.003)\end{array}$ \\
\hline pctUrbanPop & $\begin{array}{l}0.001 \\
(0.005)\end{array}$ & $\begin{array}{l}0.003 \\
(0.003)\end{array}$ & $\begin{array}{l}0.001 \\
(0.003)\end{array}$ & $\begin{array}{l}0.001 \\
(0.005)\end{array}$ & $\begin{array}{l}0.003 \\
(0.003)\end{array}$ & $\begin{array}{l}0.001 \\
(0.003)\end{array}$ & $\begin{array}{l}0.004 \\
(0.004)\end{array}$ & $\begin{array}{c}0.006^{* *} \\
(0.003)\end{array}$ & $\begin{array}{c}0.004^{*} \\
(0.003)\end{array}$ \\
\hline pctM65up & $\begin{array}{l}0.041 \\
(0.045)\end{array}$ & $\begin{array}{c}0.089^{* * *} \\
(0.032)\end{array}$ & $\begin{array}{c}0.066^{* *} \\
(0.032)\end{array}$ & $\begin{array}{l}0.033 \\
(0.045)\end{array}$ & $\begin{array}{c}0.082^{* *} \\
(0.034)\end{array}$ & $\begin{array}{c}0.059^{*} \\
(0.032)\end{array}$ & $\begin{array}{l}-.005 \\
(0.033)\end{array}$ & $\begin{array}{c}0.086^{* * *} \\
(0.032)\end{array}$ & $\begin{array}{c}0.035^{*} \\
(0.02)\end{array}$ \\
\hline pctWhite & $\begin{array}{c}0.819^{\text {**** }} \\
(0.313)\end{array}$ & $\begin{array}{c}0.408^{* *} \\
(0.193)\end{array}$ & $\begin{array}{c}0.391^{* *} \\
(0.166)\end{array}$ & $\begin{array}{c}0.974^{* * *} \\
(0.313)\end{array}$ & $\begin{array}{c}0.425^{* *} \\
(0.185)\end{array}$ & $\begin{array}{c}0.474^{* * * *} \\
(0.153)\end{array}$ & $\begin{array}{c}0.906^{* * * *} \\
(0.272)\end{array}$ & $\begin{array}{c}0.448^{* *} \\
(0.193)\end{array}$ & $\begin{array}{c}0.386^{* *} \\
(0.151)\end{array}$ \\
\hline gini & $\begin{array}{l}-.005 \\
(0.022)\end{array}$ & $\begin{array}{l}-.026 \\
(0.017)\end{array}$ & $\begin{array}{l}-.014 \\
(0.012)\end{array}$ & & & & $\begin{array}{l}-.001 \\
(0.016)\end{array}$ & $\begin{array}{l}-.019 \\
(0.016)\end{array}$ & $\begin{array}{l}-.008 \\
(0.009)\end{array}$ \\
\hline fmd & $\begin{array}{l}0.015 \\
(0.017)\end{array}$ & $\begin{array}{l}-.004 \\
(0.009)\end{array}$ & $\begin{array}{l}0.007 \\
(0.009)\end{array}$ & & & & $\begin{array}{c}0.0003 \\
(0.012)\end{array}$ & $\begin{array}{l}-.006 \\
(0.008)\end{array}$ & $\begin{array}{c}-.00009 \\
(0.007)\end{array}$ \\
\hline alcDrugDepAbuse & $\begin{array}{l}0.024 \\
(0.026)\end{array}$ & $\begin{array}{l}0.006 \\
(0.017)\end{array}$ & $\begin{array}{l}0.012 \\
(0.014)\end{array}$ & & & & $\begin{array}{l}-.005 \\
(0.024)\end{array}$ & $\begin{array}{l}-.002 \\
(0.019)\end{array}$ & $\begin{array}{l}-.002 \\
(0.014)\end{array}$ \\
\hline medHouseIncome & & & & & & & $\begin{array}{l}-.00002 \\
(1.00 \mathrm{e}-05)\end{array}$ & $\begin{array}{c}-5.47 \mathrm{e}-06 \\
(9.62 \mathrm{e}-06)\end{array}$ & $\frac{-1.00 \mathrm{e}-05^{* *}}{(6.39 \mathrm{e}-06)}$ \\
\hline pctSingleMomFams & & & & & & & $\begin{array}{l}0.012 \\
(0.008)\end{array}$ & $\begin{array}{c}-.018^{* * *} \\
(0.006)\end{array}$ & $\begin{array}{l}-.006 \\
(0.004)\end{array}$ \\
\hline pctDivorced & & & & & & & $\begin{array}{c}0.066^{* * *} \\
(0.021)\end{array}$ & $\begin{array}{c}0.031^{* *} \\
(0.013)\end{array}$ & $\begin{array}{c}0.05^{* * * *} \\
(0.012)\end{array}$ \\
\hline distToHospital & & & & & & & $\begin{array}{c}0.049^{* * *} \\
(0.015)\end{array}$ & $\begin{array}{c}0.052^{* * *} \\
(0.012)\end{array}$ & $\begin{array}{c}0.046^{* * *} \\
(0.01)\end{array}$ \\
\hline socialConnections & & & & & & & $\begin{array}{l}0.005 \\
(0.015)\end{array}$ & $\begin{array}{l}-.004 \\
(0.011)\end{array}$ & $\begin{array}{c}0.002 \\
(0.01)\end{array}$ \\
\hline lpop & $\begin{array}{c}0.969^{* * *} \\
(0.044)\end{array}$ & $\begin{array}{c}0.924^{* * *} \\
(0.031)\end{array}$ & $\begin{array}{c}0.939^{* * *} \\
(0.03)\end{array}$ & $\begin{array}{c}0.958^{* * *} \\
(0.036)\end{array}$ & $\begin{array}{l}0.9^{* * * *} \\
(0.027)\end{array}$ & $\begin{array}{c}0.926^{* * *} \\
(0.027)\end{array}$ & $\begin{array}{c}1.027^{* * * *} \\
(0.035)\end{array}$ & $\begin{array}{c}0.955^{* * *} \\
(0.028)\end{array}$ & $\begin{array}{c}0.984^{* * *} \\
(0.021)\end{array}$ \\
\hline Obs. & 150 & 150 & 150 & 150 & 150 & 150 & 150 & 150 & 150 \\
\hline$R^{2}$ & 0.964 & 0.979 & 0.984 & 0.963 & 0.978 & 0.984 & 0.977 & 0.983 & 0.99 \\
\hline$F$ statistic & 134.479 & 432.221 & 381.533 & 158.168 & 391.81 & 462.132 & 297.822 & 952.729 & 568.014 \\
\hline
\end{tabular}

Notes: OLS regressions on firearm suicide, non-firearm suicode, and overall suicide with baseline, minimal, and full specifications. All regressions have year and region fixed effects. Levels of statistical significance (with S.E. clustered by state): ${ }^{*}: 10 \%$ ** $: 5 \% \quad$ *** $: 1 \%$ 
implying a $1.4 \%$ increase in gun suicides, and a slightly stronger substitution effect, the same $1 \%$ increase in firearm ownership implying a $1.1 \%$ fall in non-gun suicides. As a result, the effect of a one percentage point increase in gun ownership rates on suicide rates is reduced from $0.5 \%$ to a no longer statistically significant $0.3 \%$.

Divorce and Distance to Hospital

Among the most interesting findings on the control variables are that the percent of divorced adults is strongly and statistically significantly correlated with all forms of suicide. A causal story from divorce to depression and suicide is plausible. Divorce also leads suicide in individual-level data (Kposowa, 2000). Depression, however, could also lead to both divorce and suicide so the causal structure requires further identification.

A second finding of importance is that suicide increases with the distance to the nearest hospital. It seems unlikely that distance to hospital is correlated with suicide attempts (and less so when one notes that this relationship is after controlling for percent urban, the poverty rate, the unemployment rate and the other control variables). Thus, the most plausible story is that distance to hospital reduces the number of attempts that are successful. This would accord with Nicholl et al.'s (2007) finding that mortality increases with distance to hospital in the case of cardiac arrest. A cost benefit analysis of hospitals should take effects of this kind into account.

\subsection{Google SEARCH MEASURE of GUN OWNERShip}

Let us now examine results from other measures of firearm ownership besides BRFSS, beginning with Google Searches for gun-related terms. This measure covers the period 2004-2009 and we use the same model and baseline specification as before. For this and later regressions, we report results in a summary form, reporting the coefficient on the gun possession only for each regression. The coefficients on other variables are qualitatively similar. The results are shown in the top section of Table 3 after a summary of the results from the BRFSS regressions we have just discussed.

Even though the Google Gun Searches measure is completely independent and there is only one overlapping year (2004), the results are broadly similar to BRFSS, having significant, positive associations for both gun and overall suicide. One difference is that the Google measure does not show signs 
of substitution between firearm and non-firearm suicide. As a result, the point estimate of the association between guns and overall suicides is higher, at $0.7 \%$ per one percentage point increase in the index, even though the effect on suicides by gun is lower, at 1.3\% (compared with 0.5 and 1.9 percents, respectively).

\subsection{Other Measures over 2000-2009}

Finally, we consider two measures of gun ownership over the complete 10 year period from 2000 to 2009. The first of these is the percentage of suicides committed by firearm. Results can be seen under the '\% / Suicides By Gun' row in the summary table (Table 3). Generally, the results from this are somewhat stronger than, but still in line with the BRFSS results. The overall effect of a one percentage point increase is greater, at $0.9 \%$; despite a stronger substitution effect, the effect on the non-gun suicide rate is $-1.2 \%$, the increased effect on gun suicides is even greater, at $3.1 \%$.

The second measure of firearm ownership for the full 10-year period is the Gun Possession Composite. Although this is composed from three sources (accidental gun deaths, NICS background checks for the purchases of firearms, and the percent of suicides by firearm), we have relatively high confidence in its ability to capture variation the single variable of interest, which is actual rates of firearm possession in the US populace.

Results are also very similar to the BRFSS measure, although slightly higher. This can be seen under the 'Gun Poss. Composite' row of the summary tables. A one percentage point rise in the index (equivalent to a one percentage point rise in the rate of firearm ownership) is associated with a slightly higher $0.8 \%$ rise in overall suicides. This is largely due to the strong effect on gun suicides at $2.3 \%$ (compared with $1.7 \%$ for BRFSS). ${ }^{14}$

\subsection{NONLINEAR EFFECTS OF GUN POSSESSION}

Like most treatments, we might expect the application of additional firearms to have diminishing effects as the prevailing rate increases. That is indeed what we find - when adding a quadratic term to the baseline regressions, we find that it is significant and negative. See Figure 4, where we have shown

\footnotetext{
${ }^{14}$ We have investigated the variation of the impact of guns on suicide over the study period and found no strong trends; annual results are presented in Appendix Figure A.1. We have also performed regressions using minimal and full specifications for the other proxies and with IVs, and found broadly similar results to these.
} 
Table 3: Firearms and Suicide summary results

\begin{tabular}{lcllll}
\hline & GunSui & \multicolumn{2}{c}{ NonGunSui } & \multicolumn{2}{c}{ Suicide } \\
\hline \multicolumn{1}{c}{ OLS } & & & & & \\
BRFSS & & & & & \\
$\quad \begin{array}{l}\text { Minimal } \\
\text { Baseline }\end{array}$ & $0.016^{* * *}(3.29)$ & $-0.007^{*}$ & $(-1.94)$ & $0.005^{*}$ & $(1.69)$ \\
$\quad \begin{array}{l}\text { Full } \\
\text { Google Gun Searches }\end{array}$ & $0.017^{* * *}(3.40)$ & $-0.008^{* *}$ & $(-2.16)$ & $0.005^{*}$ & $(1.78)$ \\
\% / Suicides By Gun & $0.013^{* * *}(4.73)$ & $-0.011^{* * *}(-3.28)$ & 0.003 & $(1.21)$ \\
Gun Poss Composite & $0.031^{* * *}(12.76)$ & -0.000 & $(-0.07)$ & $0.007^{* * *}$ & $(3.42)$ \\
\hline \multicolumn{1}{c}{ IV } & $0.023^{* * *}(8.10)$ & $-0.007^{* * *}$ & $(-2.91)$ & $0.009^{* * *}$ & $0.008^{* * *}(4.40)$ \\
BRFSS & & & & & \\
Google Gun Searches & $0.011^{* *}(2.45)$ & -0.003 & $(-0.88)$ & $0.005^{*}$ & $(1.74)$ \\
Gun Poss Composite & $0.025^{* * *}(3.22)$ & -0.005 & $(-0.91)$ & $0.010^{*}$ & $(1.90)$ \\
\hline
\end{tabular}

NoтEs: Regressions use the baseline set of controls unless otherwise noted, and include year and region fixed effects. The IV is Field and Stream magazine circulation, except for the Google Guns Regression, which uses the Google Hunting Search IV. T statistics are in parentheses. Levels of statistical significance (with S.E. clustered by state): ${ }^{*}: 10 \% \quad{ }^{* *}: 5 \%{ }^{* * *}: 1 \%$ 
how the marginal effects of gun possession on suicide vary with level. The existence of these nonlinearities suggest that changes in possession rates on the margin have the weakest effects. This result can explain why many studies show small or negligible effects from gun control in the United States (e.g. Ludwig and Cook, 2000) but others show more substantial effects from very large restrictions on gun ownership such as occurred, for example, in Australia (Leigh and Neill, 2010). The fact that gun control may only be effective when it results in very large decreases in gun ownership suggests that there may be no way of squaring the trade-off noted in the introduction between gun ownership by law-abiding hunters and other gun enthusiasts and potentially opportunistic suicides.

Figure 4: Marginal effects of guns on suicide

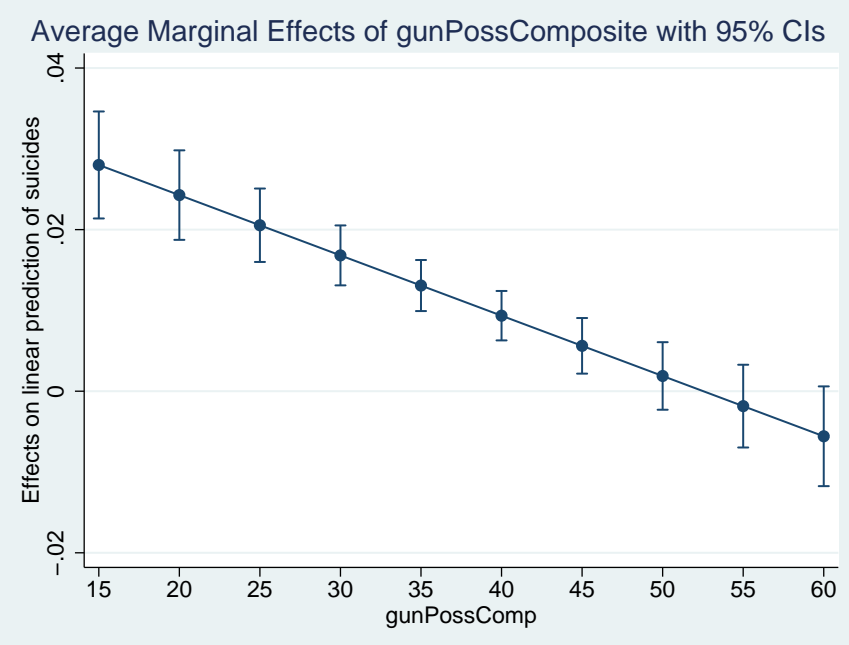

NотE: Graph shows marginal effects of gun possession composite measure of gun ownership on suicides at varying rates of ownership using the baseline specification over the 2000-2009 period, with $95 \%$ confidence intervals.

\subsection{INSTRUmental VARiables APPROACH}

Using regression to control for other variables reveals a causal effect only if we have identified all the relevant causal variables that are correlated with gun ownership. An alternative approach to causation is to use an instrumental variable, a variable that is associated with the level of firearm ownership, but that is not related to the suicide rate, except through the effect of guns. One such instrument might be "interest in hunting." Clearly those having such an interest will be more likely to have a gun. Interest 
in hunting also seems to be independent of suicides, at least after accounting for the controls we are using, such as percent urban and levels of frequent mental distress. We are not aware of any evidence that interest in hunting is directly related with suicide ${ }^{15}$. If this is correct then the exclusion restriction holds, and the instrument should not be correlated with the error term.

Using "interest in hunting" as an instrument would then allow isolating a causal effect of guns on suicides. We use two measures of interest in hunting. The first relies on revealed preference: circulation rates for a prominent hunting-related magazine. We gathered data on annual average circulation per 1000 inhabitants, disaggregated to the state level, for "Field and Stream", a popular monthly periodical about hunting and fishing (Audit Bureau of Circulations, 2012). The magazine is the most widely read magazine covering hunting in the United States by a wide margin. Baseline rates were adjusted for secular declines in overall nationwide magazine readership over the period. The second measure of hunting interest is the relative intensity of Google searches for hunting-related topics. This is available beginning in 2004 (Google, 2012), and we thus use it with the Google gun search measure of firearm possession. ${ }^{16}$

Results using two stage least squares estimation are shown in the lower section of the Summary Table 3. The first thing to note is that in all cases, the instrument is highly significant in the first stage (at the $1 \%$ significance level or above), so the instrument is indeed relevant (detailed first stage regressions are in Table A.3).

Examining the results, we see little change from OLS to IV estimates, and in no case can we reject the null of exogeneity, which makes sense given our expectations of little reverse causality for suicide. The point estimates for BRFSS and the gun possession composite are slightly higher for the 2SLS estimation compared with OLS, and Google guns searches are slightly lower ${ }^{17}$. In some cases the levels of statistical significance are lower, reflecting the lower efficiency of 2SLS estimation, but qualitative results are much the same - guns strongly affect the gun suicide rate, and while there are signs of substitution from gun

\footnotetext{
${ }^{15}$ What little evidence we can find indicates that there is either no correlation between hunting permits and violence against humans, or a negative one (Eskridge, 1986; Flynn, 2002)

${ }^{16}$ We do not present IV results for the '\% / Suicides By Firearm' measure because neither of our instruments is strong in the first stage for this measure. Also, because only one instrument is ever strong in each regression, we are unable to perform over-identification tests.

${ }^{17}$ Note that the hunting IV is capturing the variation in gun ownership owing to hunting. To the extent that hunters are more likely to own long guns than pistols, and the suicidal are less likely to use long guns in the absence of a pistol, then these results may underestimate the effect more generally of guns on suicide.
} 
to non-gun suicide, the overall effect remains positive. Taken together, these point estimates infer that $1 \%$ rise in the prevalence of guns causes a mean increase of between 0.5 and 1.0 percent in suicides. We take this as strong confirmatory evidence for our OLS results.

\section{Conclusion}

In brief, we find strong evidence that increases in gun prevalence cause an increase in firearm suicides. Despite substantial substitution of methods, we also see strong evidence that increased gun prevalence causes an increase in overall suicide. The magnitude of this result is not trivial. If all states were to reduce the rates of ownership by 10 percentage points, the expected result would be between 1640 and 2960 fewer deaths by suicide each year (5-9\% fewer, across results from our baseline OLS specification). The mean effect obscures substantial heterogeneity. When gun ownership is very high, marginal changes in ownership levels have smaller effects. Thus our non-linear results indicate that if a state with the same high levels of gun prevalence as Alabama (at 54\% ownership) but otherwise average characteristics were to reduce ownership by 10 percentage points, we would expect suicides to fall by a smaller amount than at the mean, $2.7 \%$. Reductions in firearm prevalence are increasingly effective over the range of our data, however, so if a state with median levels of gun ownership (on par with Georgia or North Carolina at 40.7\%) were to reduce ownership levels by 10 percentage points, to reach the levels currently seen in New Hampshire, suicides would be expected to fall by $13.4 \%$. These broad results hold using a wide variety of proxies for firearm ownership, across a range of control variables, and using either OLS or IV estimation.

We emphasize that we present no solution to the ecological problem. The unit of analysis is states rather than individuals which limits the quantity of data and the sources of variation we can draw upon for causal analysis. Improved measures of gun ownership and better household-level longitudinal studies would be useful to better understand the many and serious effects of firearm availability.

\section{REFERENCES}

Audit Bureau of Circulations, "Publisher's Statements," Obtained March, 2012. http://www. accessabc. com.

Azrael, Deborah, Philip J. Cook, \& Matthew Miller, "State and Local Prevalence of Firearms Own- 
ership Measurement, Structure, and Trends," Journal of Quantitative Criminology, Vol. 20, No. 1, pp. 43-62, March, 2004.

Brent, David A, Joshua A Perper, Grace Moritz, Laura liotus, Joy Schweers, lisa Balach, \& Claudia Rотн, "Familial risk factors for adolescent suicide: a case-control study," Acta Psychiatrica Scandinavica, Vol. 89, No. 1, pp. 52-58, 1994.

Bureau of Alcohol, Tobacco, Firearms and Explosives, Firearms Commerce in the United States, Washington, DC: U.S. Department of Justice, Bureau of Alcohol Tobacco and Firearms, 2011. http:// Ww. atf.gov/files/publications/firearms/121611-firearms-commerce-2011.pdf.

Bureau of Labor Statistics, "Local Area Unemployment Statistics," Accessed February, 2012. http: //www.bls.gov/lau/tables.htm.

Centers for Disease Control and Prevention, Behavioral Risk Factor Surveillance System Survey Data, Atlanta: U.S. Department of Health and Human Services, Centers for Disease Control and Prevention, 2010. http://www. cdc.gov/BRFSS/.

Centers for Disease Control and Prevention, CDC Wisqars Compressed Mortality \& Non-fatal Injury files, Atlanta: U.S. Department of Health and Human Services, Centers for Disease Control and Prevention, National Center for Injury Prevention and Control, 2012. http://www . cdc . gov/injury/ wisqars.

Choi, Hyunyoung \& Hal Varian, "Predicting the Present with Google Trends," Economic Record, Vol. 88, pp. 2-9, 2012.

Corporation for National \& Community Service, "Civic Life in America," Accessed August, 2012. http://civic.serve.gov.

Della Penna, Nicolas \& Haifang Huang, "Constructing Consumer Sentiment Index for U.S. Using Google Searches," January, 2010. University of Alberta Department of Economics Working Paper 2009-26.

Demographia, "US State Urban Shares, Population \& Density: 2000," Accessed January, 2012. www. demographia.com/db-urban2000state.htm.

Duggan, Mark, "More Guns, More Crime," The Journal of Political Economy, Vol. 109, No. 5, pp. 10861114, October, 2001.

ESKRIDGE, CHRIS W, "Zero-order Inverse Correlations Between Crimes of Violence and Hunting Licenses in the United States," Sociology and Social Research, Vol. 71, p. 55, 1986.

Federal Bureau of Investigation, "National Instant Criminal Background Check System," Accessed August, 2012. http://www.fbi.gov/about-us/cjis/nics.

Flynn, Clifton P., "Hunting and Illegal Violence Against Humans and Other Animals: Exploring the Relationship," Society and Animals, Vol. 10, No. 2, pp. 137-154, 2002.

Gallup, "Guns," Accessed April, 2011. http://www.gallup.com/poll/1645/guns . aspx.

Geneva Graduate Institute of International Studies, Small Arms Survey 2007: Guns and the City, Geneva, Switzerland: Cambridge University Press, 2007.

Google, "Google Trends," Accessed July, 2012. http://www . google. com/trends.

HAMdi, Emad, Y Amin, \& T MATtaR, "Clinical correlates of intent in attempted suicide," Acta psychiatrica scandinavica, Vol. 83, No. 5, pp. 406-411, 1991.

Hawton, Keith, "Restricting Access to Methods of Suicide," Crisis: The Journal of Crisis Intervention and Suicide Prevention, Vol. 28, No. 0, pp. 4-9, January, 2007. 
Health Forum and ESRI, "U.S. Hospitals," Vector digital data, April, 2008.

Killias, Martin, John van Kesteren, \& Martin Rindlisbacher, "Guns, Violent Crime, and Suicide in 21 Countries," Canadian Journal of Criminology, Vol. 43, p. 429, 2001.

Kleck, Gary \& E. Britt Patterson, "The impact of gun control and gun ownership levels on violence rates," Journal of Quantitative Criminology, Vol. 9, No. 3, pp. 249-287, September, 1993.

Kposowa, Augustine J, "Marital status and suicide in the National Longitudinal Mortality Study," Journal of Epidemiology and Community health, Vol. 54, No. 4, pp. 254-261, 2000.

KRUG, EG, KE Powell, \& LL DAHLBERG, "Firearm-related deaths in the United States and 35 other highand upper-middle- income countries," International Journal of Epidemiology, Vol. 27, No. 2, pp. 214 -221, April, 1998.

Leigh, Andrew \& Christine Neill, "Do Gun Buybacks Save Lives? Evidence from Panel Data," American Law and Economics Review, Vol. 12, No. 2, pp. 509-557, Fall, 2010.

Lubin, Gad, Nomi Werbeloff, Demian Halperin, Mordechai Shmushrevitch, Mark Weiser, \& Haim Y. KNoBlen, "Decrease in Suicide Rates After a Change of Policy Reducing Access to Firearms in Adolescents: A Naturalistic Epidemiological Study," Suicide and Life-Threatening Behavior, Vol. 40, No. 5, pp. 421-Ü424, 2010.

Ludwig, Jens \& PhiliP J Cook, "Homicide and suicide rates associated with implementation of the Brady Handgun Violence Prevention Act," JAMA: The Journal of the American Medical Association, Vol. 284, No. 5, pp. 585-591, 2000.

National Academy of Sciences, National Research Council, Firearms and Violence: A Critical Review, Washington, DC: The National Academies Press, 2004. http://www.nap.edu/openbook.php? record $\backslash$ id $=10881 \backslash$ \&page $=1$.

Nicholl, Jon, James West, Steve Goodacre, \& Janette Turner, "The relationship between distance to hospital and patient mortality in emergencies: an observational study," Emergency Medicine Journal, Vol. 24, No. 9, pp. 665-668, 2007.

Nisbett, Richard E \& Dov Cohen, Culture of honor: The psychology of violence in the South.: Westview Press, 1996.

Owens, David, Judith Horrocks, \& Allan House, "Fatal and non-fatal repetition of self-harm - a systematic review," The British Journal of Psychiatry, Vol. 181, No. 3, pp. 193-199, 2002.

Peterson, Linda G, McKim Peterson, Gregory J O'Shanick, \& Alan Swann, "Self-inflicted gunshot wounds: Lethality of method versus intent.," The American Journal of Psychiatry, Vol. 142, pp. 228231, 1985

Rosenfeld, Richard, Steven F. Messner, \& Eric P. Baumer, "Social Capital and Homicide," Social Forces, Vol. 80, No. 1, pp. 283-310, September, 2001.

Shenassa, Edmond D, Constantine Daskalakis, \& Stephen L Buka, "Utility of indices of gun availability in the community," Journal of Epidemiology and Community Health, Vol. 60, No. 1, pp. 44-49, January, 2006.

Simon, Thomas R., Alan C. Swann, Kenneth E. Powell, Lloyd B. Potter, Marcie-Jo Kresnow, \& Patrick W. O'CARroll, "Characteristics of Impulsive Suicide Attempts and Attempters," Suicide and Life-Threatening Behavior, Vol. 32, pp. 49-59, 2002.

Skopek, Michaela A \& Richard Perkins, "Deliberate exposure to motor vehicle exhaust gas: the psychosocial profile of attempted suicide," Australasian Psychiatry, Vol. 32, No. 6, pp. 830-838, 1998. 
Sloan, John Henry, Frederick P. Rivara, Donald T. Reay, James A.J. Ferris, \& Arthur L. Kellermann, "Firearm Regulations and Rates of Suicide," New England Journal of Medicine, Vol. 322, No. 6, pp. 369-373, 1990. PMID: 2393410.

Smith, Tom W., Peter Marsden, Michael Hout, \& Jibum Kim, General social surveys, 1972-2010 [machine-readable data file], Chicago: National Opinion Research Center, 2011.

Substance Abuse and Mental Health Services Administration, "National Survey on Drug Use and Health, National Household Survey on Drug Abuse," Accessed June, 2012. http: //www . samhsa. gov/data/NSDUH . aspx.

US Census Bureau, "American Community Surveys, Census 2000, Census 2010," Accessed April, $2012 a$. http://factfinder2 . census.gov.

US Census Bureau, "2012 Statistical Abstract," Accessed January, 2012b. http: //www . census . gov/ compendia/statab.

US Census Bureau, "Census 2000 Census Tracts," Accessed January, 2012c. http: //www. census . gov/geo/www/tractez.html.

US Census Bureau, "Census Small Area Income and Poverty Estimates," Accessed January, 2012d. http://www. census.gov/did/www/saipe/data/statecounty/data.

Vernick, Jon S \& Lisa M Hepburn, Evaluating gun policy: Effects on crime and violence, Chap. State and federal gun laws: trends for 1970-99, pp. 345-411, Washington, DC: Brookings Institution Press, 2003.

Vyrostek, Sara B., Joseph L. Annest, \& George W. Ryan, "Surveillance for Fatal and Nonfatal Injuries — United States, 2001," September, 2004. CDC Surveillance Reports http://www . cdc .gov/mmwr/ preview/mmwrhtml/ss5307a1.htm\#tab12.

Wintemute, Garen J., Carrie A. Parham, James Jay Beaumont, Mona Wright, \& Christiana Drake, "Mortality among Recent Purchasers of Handguns," New England Journal of Medicine, Vol. 341, No. 21, pp. 1583-1589, 1999.

\section{A Supplementary tables}

Table A.1: Summary statistics

\begin{tabular}{|c|c|c|c|c|c|}
\hline Variable & Mean & (Std. Dev.) & Min. & Max. & $\mathbf{N}$ \\
\hline $\begin{array}{l}\text { Non-firearm Suicides (CDC) - ICD E-codes } \\
\text { X60-71, X75-84, Y87.0 }\end{array}$ & 312.76 & $(342.64)$ & 22 & 2304 & 500 \\
\hline Firearm Suicides (CDC) - ICD E-codes X72-X74 & 344.62 & $(317.82)$ & 12 & 1583 & 500 \\
\hline Firearm in household (BRFSS) & 38.73 & $(13.8)$ & 8.72 & 65.5 & 150 \\
\hline$\%$ of Suicides by Gun & 53.3 & $(12.46)$ & 14.29 & 78.10 & 500 \\
\hline NICS Background Checks per 100,000 (DOJ) & 3204.71 & $(1769.93)$ & 0 & 8420.19 & 500 \\
\hline $\begin{array}{l}\text { Accidental Deaths By Firearm per 100,000 (CDC) } \\
\text { - ICD E-codes W32-W34 }\end{array}$ & 0.28 & $(0.25)$ & 0 & 1.41 & 500 \\
\hline Gun Poss. Composite (1st Principal Comp. of & 38 & $(11.5)$ & 11.55 & 70.65 & 500 \\
\hline
\end{tabular}


... table A.1 continued

\begin{tabular}{|c|c|c|c|c|c|}
\hline Variable & Mean & (Std. Dev.) & Min. & Max. & $\mathbf{N}$ \\
\hline $\begin{array}{l}\text { gunCompSearches pctSuicideByGun accGunDeath) } \\
\text { Google 'Gun Rifle Pistol Handgun' Searches }\end{array}$ & 36.61 & $(14.14)$ & 6.06 & 85.2 & 300 \\
\hline Field \& Stream Monthly Circulation per 100,000 (ABC) & 761.84 & $(325.33)$ & 126.82 & 1696.19 & 500 \\
\hline 'Hunting' Google Searches & 38.54 & $(18.07)$ & 13.3 & 94.49 & 300 \\
\hline Intercensal Population estimate, July 1 (Census) & 5875844.71 & $(6452197.2)$ & 494300 & 36961229 & 500 \\
\hline$\%$ white race alone (census) & 0.82 & $(0.12)$ & 0.26 & 0.97 & 500 \\
\hline $\begin{array}{l}\text { \% Past Year Dep. on or Abuse of } \\
\text { Drugs or Alc. }(12+) \text { (SAMHSA - NHSDA/NHDUH) }\end{array}$ & 8.89 & $(1.39)$ & 5.14 & 12.25 & 500 \\
\hline$\%$ pop'n male, $65+$ & 5.38 & $(0.73)$ & 2.73 & 7.63 & 500 \\
\hline$\%$ under poverty line, all ages (census) & 12.3 & (3.04) & 5.60 & 21.8 & 500 \\
\hline Median household income (census) & 45899.05 & $(7993.84)$ & 30187 & 70482 & 500 \\
\hline Annual average unemployment rate in state (BLS) & 5.16 & $(1.67)$ & 2.3 & 13.3 & 500 \\
\hline$\%$ /Families w/ children having a single female $\mathrm{HOH}$ & 22.6 & $(3.94)$ & 11.02 & 35.62 & 500 \\
\hline$\%$ Divorced $>15$ (ACS-census) & 10.67 & (1.37) & 7.52 & 14.37 & 500 \\
\hline$\%$ having Frequent Mental Distress (BRFSS) & 9.9 & $(1.78)$ & 4.31 & 18.71 & 500 \\
\hline $\begin{array}{l}\text { Gini coeff/ income ineq for households } \\
>\$ 0 \text { (ACS PUMA via IPUMS) }\end{array}$ & 43.8 & $(1.97)$ & 38.05 & 49.58 & 500 \\
\hline \% Urban Land area*, 2000 (census) & 6.62 & $(9.68)$ & 0.05 & 37.59 & 500 \\
\hline \% Urban Population*, 2000 (census) & 71.69 & $(14.77)$ & 38.18 & 94.44 & 500 \\
\hline Pop'n weighted avg dist to hospital ER* (miles) & 5.26 & $(1.81)$ & 2.99 & 15.73 & 500 \\
\hline $\begin{array}{l}\text { Social Connections - Comp. of group involvement \& } \\
\text { interactions w/ neighbors* (Civic Life in America) }\end{array}$ & -0.01 & $(1.32)$ & -4.05 & 3.25 & 500 \\
\hline
\end{tabular}


Table A.2: BRFSS firearm ownership and suicide (sample is mean of 2001,2,4; baseline controls)

\begin{tabular}{|c|c|c|c|}
\hline & GunSui & NonGSui & Suicide \\
\hline & (1) & (2) & (3) \\
\hline guninhouse & $\begin{array}{c}0.018^{* * *} \\
(0.006)\end{array}$ & $\begin{array}{c}.007^{*} \\
(0.004)\end{array}$ & $\begin{array}{c}0.007^{*} \\
(0.004)\end{array}$ \\
\hline povertyRate & $\begin{array}{l}-.019 \\
(0.026)\end{array}$ & $\begin{array}{l}-.007 \\
(0.018)\end{array}$ & $\begin{array}{l}-.008 \\
(0.016)\end{array}$ \\
\hline unemployment & $\begin{array}{l}0.057 \\
(0.042)\end{array}$ & $\begin{array}{l}0.029 \\
(0.033)\end{array}$ & $\begin{array}{l}0.035 \\
(0.031)\end{array}$ \\
\hline pctUrbanLand & $\begin{array}{c}-.015^{* *} \\
(0.008)\end{array}$ & $\begin{array}{c}-.007^{* * *} \\
(0.003)\end{array}$ & $\begin{array}{c}-.008^{* *} \\
(0.004)\end{array}$ \\
\hline pctUrbanPop & $\begin{array}{l}0.002 \\
(0.006)\end{array}$ & $\begin{array}{l}0.003 \\
(0.003)\end{array}$ & $\begin{array}{l}0.002 \\
(0.004)\end{array}$ \\
\hline pctM65up & $\begin{array}{l}0.053 \\
(0.051)\end{array}$ & $\begin{array}{c}0.097^{* * *} \\
(0.035)\end{array}$ & $\begin{array}{c}0.076^{* *} \\
(0.035)\end{array}$ \\
\hline pctWhite & $\begin{array}{c}0.699^{*} \\
(0.371)\end{array}$ & $\begin{array}{l}0.304 \\
(0.215)\end{array}$ & $\begin{array}{c}0.264 \\
(0.19)\end{array}$ \\
\hline gini & $\begin{array}{l}-.009 \\
(0.035)\end{array}$ & $\begin{array}{c}-.034^{*} \\
(0.019)\end{array}$ & $\begin{array}{l}-.019 \\
(0.019)\end{array}$ \\
\hline fmd & $\begin{array}{l}0.022 \\
(0.025)\end{array}$ & $\begin{array}{l}-.001 \\
(0.013)\end{array}$ & $\begin{array}{l}0.014 \\
(0.014)\end{array}$ \\
\hline alcDrugDepAbuse & $\begin{array}{l}0.042 \\
(0.053)\end{array}$ & $\begin{array}{l}0.038 \\
(0.029)\end{array}$ & $\begin{array}{l}0.036 \\
(0.027)\end{array}$ \\
\hline lpop & $\begin{array}{c}0.976^{* * *} \\
(0.06)\end{array}$ & $\begin{array}{c}0.941^{* * *} \\
(0.033)\end{array}$ & $\begin{array}{c}0.954^{* * *} \\
(0.039)\end{array}$ \\
\hline Obs. & 50 & 50 & 50 \\
\hline$R^{2}$ & 0.971 & 0.987 & 0.988 \\
\hline$F$ statistic & 123.36 & 303.139 & 309.688 \\
\hline
\end{tabular}

Notes: All regressions have region fixed effects. Levels of statistical significance (with heteroscedasticity robust S.E): $\quad{ }^{*}: 10 \%$ ** : $5 \% \quad{ }^{* * *}: 1 \%$ 
Table A.3: IV First Stage results

\begin{tabular}{|c|c|c|c|}
\hline & BRFSS-Sui & Google-Sui & GunPossComp-Sui \\
\hline & (1) & (2) & (3) \\
\hline lfsCircRate & $\begin{array}{c}19.044^{* * *} \\
(3.178)\end{array}$ & & $\begin{array}{c}10.847^{* * *} \\
(3.413)\end{array}$ \\
\hline lhuntSearches & & $\begin{array}{c}27.562^{* * * *} \\
(3.386)\end{array}$ & \\
\hline povertyRate & $\begin{array}{c}1.314^{* * *} \\
(0.352)\end{array}$ & $\begin{array}{l}-.318 \\
(0.468)\end{array}$ & $\underset{(0.421)}{1.120^{* * *}}$ \\
\hline unemployment & $\begin{array}{l}-.090 \\
(0.886)\end{array}$ & $\begin{array}{l}0.904 \\
(0.657)\end{array}$ & $\begin{array}{l}-.576 \\
(0.501)\end{array}$ \\
\hline pctUrbanLand & $\begin{array}{l}-.057 \\
(0.082)\end{array}$ & $\begin{array}{l}-.051 \\
(0.113)\end{array}$ & $\begin{array}{l}-.027 \\
(0.125)\end{array}$ \\
\hline pctUrbanPop & $\begin{array}{l}-.127 \\
(0.106)\end{array}$ & $\underset{(0.13)}{0.273^{* *}}$ & $\begin{array}{l}-.150 \\
(0.134)\end{array}$ \\
\hline pctM65up & $\begin{array}{c}-1.116 \\
(1.086)\end{array}$ & $\begin{array}{c}0.94 \\
(1.285)\end{array}$ & $\begin{array}{c}-1.217 \\
(1.026)\end{array}$ \\
\hline pctWhite & $\begin{array}{l}5.380 \\
(7.036)\end{array}$ & $\begin{array}{c}15.146^{* *} \\
(6.775)\end{array}$ & $\begin{array}{l}3.667 \\
(8.287)\end{array}$ \\
\hline gini & $\begin{array}{l}-.728^{*} \\
(0.439)\end{array}$ & $\begin{array}{l}0.288 \\
(0.642)\end{array}$ & $\begin{array}{l}0.454 \\
(0.471)\end{array}$ \\
\hline fmd & $\begin{array}{l}-.077 \\
(0.284)\end{array}$ & $\begin{array}{c}1.121^{* *} \\
(0.496)\end{array}$ & $\begin{array}{c}0.782^{* *} \\
(0.357)\end{array}$ \\
\hline alcDrugDepAbuse & $\begin{array}{c}-1.134^{* *} \\
(0.451)\end{array}$ & $\begin{array}{l}-.127 \\
(0.847)\end{array}$ & $\begin{array}{l}-.400 \\
(0.552)\end{array}$ \\
\hline lpop & $\begin{array}{l}-.659 \\
(0.955)\end{array}$ & $\begin{array}{l}-.078 \\
(1.547)\end{array}$ & $\begin{array}{l}-.955 \\
(1.017)\end{array}$ \\
\hline Obs. & 150 & 300 & 500 \\
\hline$R^{2}$ & 0.92 & 0.86 & 0.81 \\
\hline$F$ statistic & 123.882 & 161.666 & 41.449 \\
\hline
\end{tabular}

Notes: The dependent variable is BRFSS guninhouse for regressions 1 \& 2, Google Gun Possession for regressions 3 \& 4, and the Gun Possession Composite for regressions $5 \& 6$. All regressions use the baseline specifications, including year and region fixed effects. Levels of statistical significance (with clustered S.E.): $\quad *: 10 \% \quad{ }^{* *}: 5 \% \quad{ }^{* * *}: 1 \%$ 
Figure A.1: Annual trends in association between guns and suicide, 2000-2009

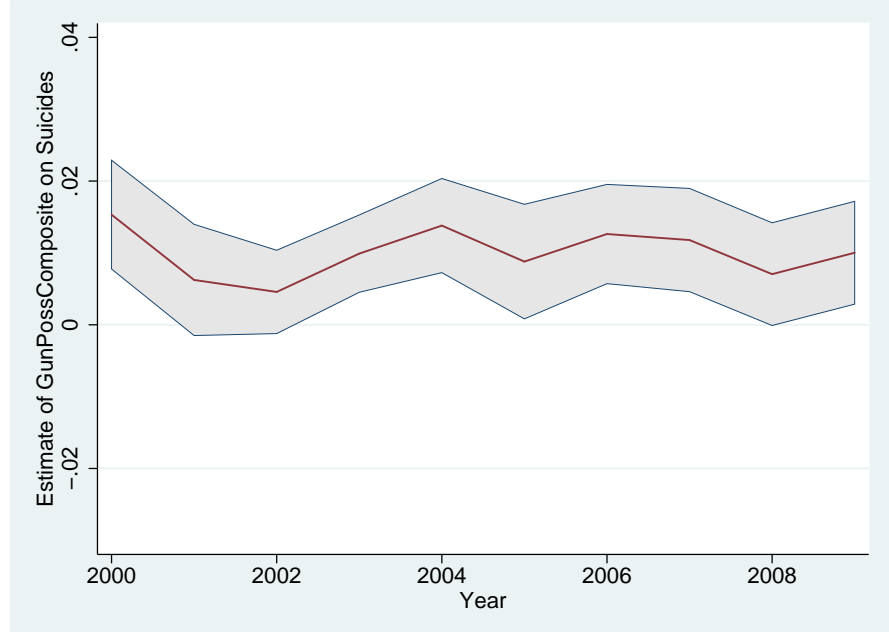

Nоте: Graph shows coefficient of gun possession composite on suicides in annual single-year regressions from 2000-2009 using the baseline specification, with $95 \%$ confidence intervals. 